\title{
An Intuitionistic Fuzzy Stochastic Decision-Making Method Based on Case-Based Reasoning and Prospect Theory
}

\author{
Peng Li, ${ }^{1}$ Yingjie Yang, ${ }^{2}$ and Cuiping $\mathrm{Wei}^{3}$ \\ ${ }^{1}$ College of Economics and Management, Jiangsu University of Science and Technology, Zhenjiang, Jiangsu 212003, China \\ ${ }^{2}$ School of Computer Science and Informatics, De Montfort University, The Gateway, Leicester LE1 9BH, UK \\ ${ }^{3}$ College of Mathematic Sciences, Yangzhou University, Jiangsu 225002, China
}

Correspondence should be addressed to Cuiping Wei; wei_cuiping@aliyun.com

Received 23 January 2017; Revised 23 March 2017; Accepted 30 March 2017; Published 24 April 2017

Academic Editor: Franck Massa

Copyright (C) 2017 Peng Li et al. This is an open access article distributed under the Creative Commons Attribution License, which permits unrestricted use, distribution, and reproduction in any medium, provided the original work is properly cited.

\begin{abstract}
According to the case-based reasoning method and prospect theory, this paper mainly focuses on finding a way to obtain decisionmakers' preferences and the criterion weights for stochastic multicriteria decision-making problems and classify alternatives. Firstly, we construct a new score function for an intuitionistic fuzzy number (IFN) considering the decision-making environment. Then, we aggregate the decision-making information in different natural states according to the prospect theory and test decision-making matrices. A mathematical programming model based on a case-based reasoning method is presented to obtain the criterion weights. Moreover, in the original decision-making problem, we integrate all the intuitionistic fuzzy decision-making matrices into an expectation matrix using the expected utility theory and classify or rank the alternatives by the case-based reasoning method. Finally, two illustrative examples are provided to illustrate the implementation process and applicability of the developed method.
\end{abstract}

\section{Introduction}

Multicriteria decision-making (MCDM) mainly searches for the most satisfactory solutions from finite alternatives under conflicting criteria. With the increasing complexity of socioeconomic environments, it is very hard for decision-makers (DMs) to express their preferences with crisp values. Fuzzy set (FS) theory was proposed and has been deeply studied from different disciplines [1-7].

Atanassov [8] introduced the concept of intuitionistic fuzzy sets (IFSs) as an extension of FS theory. Vahdani et al. [9] proposed a novel ELECTRE method to deal with intuitionistic fuzzy group decision-making problems. Hashemi et al. [10] put forward a compromise ratio approach for water resources management based on IFS. Mousavi et al. [11] constructed a VIKOR decision-making model for addressing intuitionistic fuzzy group decision-making problems. Mousavi et al. [12] introduced the difficulties in selection issues for manufacturing firms and used grey incidence method and IFS to solve them. Chen and Chang [13] constructed a novel type of similarity measure between
IFSs and applied it to pattern recognition. Song et al. [14] proposed a new distance measure for IFSs by D-S theory. Xu and Liao [15] discussed the decision-making methods for IF preference relations.

To deal with more fuzzy decision-making problems, many researchers studied interval-valued intuitionistic fuzzy decision-making methods. Hashemi et al. [16] introduced a novel compromise ratio decision-making model in an interval-valued intuitionistic fuzzy environment. Wang et al. [17] studied the defects of the present score functions for IVIFNs and proposed a novel one based on prospect theory (PT). Cao et al. [18] developed a new decisionmaking model for interval-valued intuitionistic stochastic information by using set pair analysis. Wang et al. [19] researched a new decision-making model for interval-valued intuitionistic linguistic numbers. Yu et al. [20] developed an extended TODIM decision-making method for intuitionistic linguistic numbers. Wan and $\mathrm{Li}$ [21] proposed a novel mathematical programming to solve heterogeneous decisionmaking information. 
For stochastic fuzzy decision-making problems, some methods for deriving the weights of criteria and ranking alternatives have been proposed. Wang and $\mathrm{Li}$ [22] put forward a decision-making approach based on score functions. Li et al. [23] put forward some stochastic multicriteria decisionmaking methods for IFNs. Zhou et al. [24-26] proposed some new decision-making approaches for stochastic extended grey numbers decision problems by prospect theory and regret theory.

We note that these methods are based on the information of decision-making problems themselves to determinate the weights of criteria and rank the alternatives. However, for some very complex decision-making problems, if we can use the data from historically successful decision-making cases to help decision-making, then the method would be more reasonable. Motivated by this idea, the case-based reasoning $(\mathrm{CBR})$ and prospect theory $(\mathrm{PT})$ are used to realize our goal.

Case-based reasoning (CBR) is an effective approach to obtain preferential information from the DMs' decisions on selected cases. In recent years, there has been much research on CBR methods. Chen et al. [27] discussed a new CBR method for MCDM with crisp values. Chen and Chiu [28] use CBR models to solve service-oriented value chain design making problems. Koo and Hong [29] constructed a CBR method to capture the energy performance curve. Yan et al. [30] put forward a group decisionmaking method using the CBR method and applied it to waste water treatment. Fan et al. [31] proposed a CBR method to solve project risk management. Evans [32] studied the business management education issues by case-based assessment.

Based on CBR and PT, this paper aims to propose a new method for stochastic intuitionistic fuzzy decisionmaking problems in order to overcome the aforementioned two limitations. We first put forward a new score function for IFNs. The existing score functions mainly focus on distributing the hesitancy degree by various methods without considering the decision-making environment. If the decision-making matrix is determined, the decisionmaking results by those traditional score functions are the same no matter what the decision-making situation is. The proposed score function is suitable for some special decisionmaking environments, such as investing in an $\mathrm{R} \& \mathrm{D}$ project. By the PT and grey incidence analysis (GIA), we construct a mathematical programming model to calculate the weights of criteria according to the idea of CBR based on the test matrices. Moreover, on the basis of the weights of criteria and threshold values obtained by CBR, we use the EU to aggregate information in all natural states and the idea of CBR to rank the alternatives. The main contributions of this study are mentioned as follows:

(i) A new score function is proposed that considers the decision environment.

(ii) A novel decision pattern is put forward that uses CBR method by the aid of the historical successful decision cases and PT by considering DMs' bounded rationality. (iii) Construct a mathematical programming model according to the idea of CBR and GIA, by which the clustering or ranking of alternatives is obtained.

The rest of this paper is organized as follows. Section 2 introduces the information regarding the concepts about IFSs, the new score function, PT, and GIA. Section 3 summarizes the main idea of CBR and proposes a CBR model for IFS based on the prospect theory. Section 4 gives an illustrative example for a venture capital company investing in an $R \& D$ project. Section 5 summarizes the findings and suggests a possible extension of future research.

\section{Preliminaries}

\subsection{Intuitionistic Fuzzy Set}

Definition 1 ((IFS) [8]). Let $X$ be a universe of discourse. An intuitionistic fuzzy set in $X$ can be expressed as $A=$ $\left\{\left\langle x, u_{A}(x), v_{A}(x)\right\rangle \mid x \in X\right\}$, where $u_{a}: X \rightarrow[0,1], v_{a}: X \rightarrow$ $[0,1]$ with the condition $0 \leq u_{A}(x)+v_{A}(x) \leq 1, \forall x \in X$. $u_{A}(x), v_{A}(x)$ are called the membership and nonmembership degree functions of $x$ to $A$, respectively, where $u_{A}(x) \in[0,1]$, $v_{A}(x) \in[0,1]$.

For an IFS $A$, we call $\pi_{A}(x)=1-u_{A}(x)-v_{A}(x)$ the hesitancy degree, representing the degree of indeterminacy of $x$ to $A$. It is obviously observed that $0 \leq \pi_{A}(x) \leq 1$.

For convenience, $a=\left\langle u_{a}, v_{a}\right\rangle$ is called an intuitionistic fuzzy number (IFN). The operational laws of IFNs are presented as follows [33].

Let $a=\left\langle u_{a}, v_{a}\right\rangle$ and $b=\left\langle u_{b}, v_{b}\right\rangle$ be any two IFNs; then

(1) $a \oplus b=\left\langle u_{a}+u_{b}-u_{a} u_{b}, v_{a} v_{b}\right\rangle$;

(2) $a \otimes b=\left\langle u_{a} u_{b}, v_{a}+v_{b}-v_{a} v_{b}\right\rangle$;

(3) $\lambda a=\left\langle 1-\left(1-u_{a}\right)^{\lambda}, v_{a}^{\lambda}\right\rangle, \lambda>0$;

(4) $a^{\lambda}=\left\langle u_{a}^{\lambda}, 1-\left(1-v_{a}\right)^{\lambda}\right\rangle, \lambda>0$.

Definition 2 ((IFWA) [33]). Let $a=\left(a_{1}, a_{2}, \ldots, a_{n}\right)$, where $a_{j}=\left\langle u_{j}, v_{j}\right\rangle$ is a collection of IFNs. An intuitionistic fuzzy weighted averaging (IFWA) operator is defined by

$$
\begin{aligned}
& \operatorname{IFWA}\left(a_{1}, a_{2}, \ldots, a_{n}\right)=w_{1} a_{1} \oplus w_{2} a_{2} \oplus \cdots \oplus w_{n} a_{n} \\
& =\left(1-\prod_{j=1}^{n}\left(1-u_{j}\right)^{w_{j}}, \prod_{j=1}^{n} v_{j}{ }^{w_{j}}\right)
\end{aligned}
$$

where $w=\left(w_{1}, w_{2}, \ldots, w_{n}\right)$ is the weighting vector of $a$, with $w_{j} \geq 0$ and $\sum_{j=1}^{n} w_{j}=1$.

2.2. Score Functions for IFNs. Let $a=\left\langle u_{a}, v_{a}\right\rangle$ be an IFN; the score function of $a$, as a tool to compare two given IFNs, is proposed by Chen and Tan [34] in 1994 as follows:

$$
S(a)=u_{a}-v_{a}
$$

Let $a$ and $b$ be IFNs; if $S(a)<S(b)$, then $a$ is smaller than $b$, denoted by $b>a$. 
Example 3. Let $a=\langle 0.3,0.2\rangle$ and $b=\langle 0.4,0.3\rangle$ be two IFNs. By using (2), we can obtain that $S(a)=S(b)=0.1$. It is obvious that the above score function cannot discern the values between two IFNs in some cases.

Later, Ye [35] proposed a new score function as follows:

$$
S(\alpha)=u_{\alpha}-v_{\alpha}+\lambda \pi_{\alpha}, \quad \lambda \in[-1,1] .
$$

For the IFNs $a=\langle 0.3,0.2\rangle$ and $b=\langle 0.4,0.3\rangle$ in Example 3, by (3), we can obtain

$$
\begin{aligned}
& S(a) \geq S(b), \quad \text { when } \lambda \geq 0, \\
& S(a)<S(b), \quad \text { when } \lambda<0 .
\end{aligned}
$$

The main problem of using (3) lies in the acquisition of the exact value of parameter $\lambda$.

In this paper, we propose the following new score function.

Definition 4. Let $a_{1}=\left\langle u_{1}, v_{1}\right\rangle, a_{2}=\left\langle u_{2}, v_{2}\right\rangle, \ldots, a_{n}=\left\langle u_{n}, v_{n}\right\rangle$ be $n$ IFNs. The new score function of $a_{i}$ can be mathematically expressed as

$$
S_{\text {new }}\left(a_{i}\right)=u_{i}-v_{i}+\frac{\theta_{i}-1}{\theta_{i}+1}\left(1-u_{i}-v_{i}\right) \text {, }
$$

where $\theta_{i}=\left(u_{i} / v_{i}\right) /\left(\sum_{i=1}^{m} u_{i} / \sum_{i=1}^{m} v_{i}\right)$.

Remark 5. If $v_{i}=0$ and $\sum_{i=1}^{m} v_{i} \neq 0$, then $\left(\theta_{i}-1\right) /\left(\theta_{i}+1\right)=1$; if $\sum_{i=1}^{m} v_{i}=0$, then $\left(\theta_{i}-1\right) /\left(\theta_{i}+1\right)=0$.

In fact, this score function considers both the ratio of membership degree and nonmembership degree for certain IFN and those of all compared IFNs.

Example 6. Let $a_{1}=\langle 0.4,0.4\rangle, a_{2}=\langle 0.3,0.3\rangle$, and $a_{3}=$ $\langle 0.4,0.5\rangle$ be three IFNs.

By (5) we can obtain that $S_{\text {new }}\left(a_{1}\right)=0.009, S_{\text {new }}\left(a_{2}\right)=$ 0.018 , and $S_{\text {new }}\left(a_{3}\right)=-0.12$. Thus $a_{2}>a_{1}>a_{3}$.

By (3) in [35], we can obtain

$$
\begin{aligned}
& S\left(a_{1}\right)=S\left(a_{2}\right)>S\left(a_{3}\right), \quad \text { when } \lambda=0, \\
& S\left(a_{2}\right)>S\left(a_{1}\right)>S\left(a_{3}\right), \quad \text { when } \lambda=0.5, \\
& S\left(a_{1}\right)>S\left(a_{3}\right)>S\left(a_{2}\right), \quad \text { when } \lambda=-0.5 .
\end{aligned}
$$

The score function [35] receives different ranking for IFNs with different parameters, while (5) does not involve the choice of parameters. Moreover it takes into consideration the decision-making environment. For instance, there are eleven teams $\left(T_{1}, T_{2}, \ldots, T_{11}\right)$ in the course of a single-recycling game. Every team has ten games. Owing to the calendar, $T_{1}$ won four matches and lost four. Meanwhile, $T_{2}$ won three and lost three and $T_{3}$ won four and lost five. The results can be described by the three IFNs as follows: $a_{1}=\langle 0.4,0.4\rangle$, $a_{2}=\langle 0.3,0.3\rangle$, and $a_{3}=\langle 0.4,0.5\rangle$. All the teams have an average win rate under $50 \%$ because other teams have not played any game. $T_{2}$ will face four matches while $T_{1}$ two.

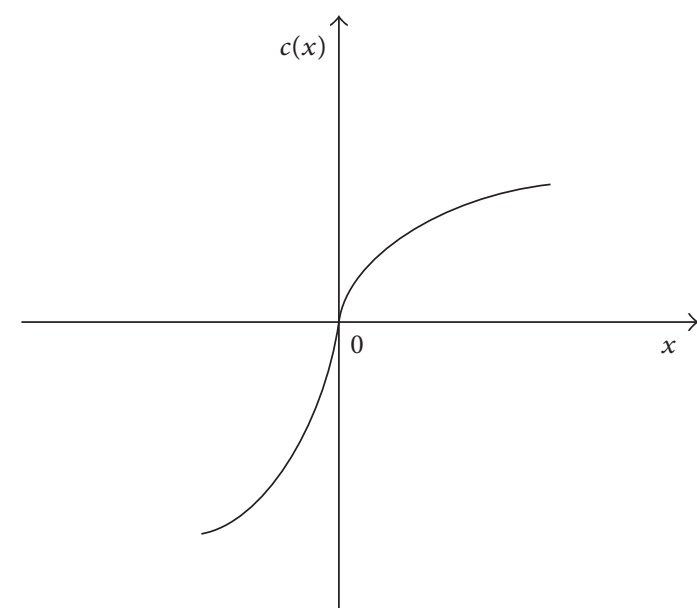

Figure 1: An S-shaped value function.

Both $T_{1}$ and $T_{2}$ have a large chance to beat their opponents because their win rate is just $50 \%$. Both $T_{1}$ and $T_{2}$ will most likely obtain the results as $\langle 0.6,0.4\rangle$ and $\langle 0.7,0.3\rangle$, respectively; that is, $a_{2}=\langle 0.3,0.3\rangle$ is most likely bigger than the others.

2.3. Prospect Theory. The prospect theory (PT) can explain individual's bounded rationality behavior. Since the appearance of PT, more and more researchers have carried out high number of studies [36-40]. PT can be described briefly as follows.

DMs make a decision mainly according to the prospect value. The prospect value is codetermined by both value function and probability weight function:

$$
W=\sum_{i=1}^{n} h\left(p_{i}\right) c\left(x_{i}\right),
$$

where $h\left(p_{i}\right)$ and $c\left(x_{i}\right)$ are called the probability weight function and the value function, respectively.

The probability weight function is a mathematical function of the probability $p$ and is shown as follows:

$$
h(p)=\frac{p^{\gamma}}{\left(p^{\gamma}+(1-p)^{\gamma}\right)^{1 / \gamma}}
$$

where $\gamma$ is the risk gain attitude coefficient.

The value function reflects the deviations from the reference point and is described by an S-shaped value function (see Figure 1). The form of the value function can be expressed as

$$
c(x)= \begin{cases}x^{\delta}, & x \geq 0 \\ -\sigma(-x)^{\beta}, & x<0\end{cases}
$$

where $\delta$ and $\beta$ determine the concavity and convexity, respectively $(0<\delta<1,0<\beta<1), \sigma$ reflects the loss aversion $(\sigma>1)$, and $x$ is the deviation from the reference point. 
According to Zhou et al. [26], the parameters are $\gamma=$ $0.61, \delta=\beta=0.88$, and $\sigma=-2.25$. These parameters are obtained by performing numerous experiments that reflect the bounded rationality of DM. This explains why DM usually overestimates small probabilities and risk avoidance problems. $\gamma=0.61$ means that probability weight function is larger than real probability for small probabilities. $\delta=\beta=$ 0.88 and $\sigma=-2.25$ mean that DM is more sensitive to loss than gain.

2.4. Grey Incidence Analysis (GIA). The grey incidence analysis (GIA) is one of the well-known methods to evaluate different relationships among discrete data series. The definition of the GIA is expressed as follows.

Definition 7 (see [41]). Let $X$ be a decision-making factor set of grey relations, $x_{0} \in X$ be the referential sequence, and $x_{i} \in X$ be the comparative sequence with $x_{0}(k)$ and $x_{i}(k)$ being the numerals at point $k$ for $x_{0}$ and $x_{i}$, respectively. If $r\left(x_{0}(k), x_{i}(k)\right)$ and $r\left(x_{0}, x_{i}\right)$ are real numbers, which satisfy the following four grey axioms, then $r\left(x_{0}(k), x_{i}(k)\right)$ is defined as the grey relational coefficient of these factors in point $k$, and the grade of grey relation $r\left(x_{0}, x_{i}\right)$ is the average value of $r\left(x_{0}(k), x_{i}(k)\right)$.

(1) Norm Interval. $0<r\left(x_{0}, x_{i}\right) \leq 1, \forall k ; r\left(x_{0}, x_{i}\right)=1$, if $x_{0}=$ $x_{i} ; r\left(x_{0}, x_{i}\right)=0$, if $x_{0}, x_{i} \in \Phi$, where $\Phi$ is an empty set.

(2) Duality Symmetric. $x, y \in X \Rightarrow r(x, y)=r(y, x)$, if $X=$ $\{x, y\}$.

(3) Wholeness. $r\left(x_{i}, x_{j}\right) \stackrel{\text { often }}{\neq} r\left(x_{j}, x_{i}\right)$, if $X=\left\{x_{i} \mid i=\right.$ $0,1,2, \ldots, n\}, n>2$.

(4) Approachability. $r\left(x_{0}(k), x_{i}(k)\right)$ decreases along with $\left|x_{0}(k)-x_{i}(k)\right|$ increasing.

Traditional grey relation coefficient is expressed by

$$
\begin{aligned}
& r\left(x_{0}(k), x_{i}(k)\right) \\
& =\frac{\min _{i} \min _{k}\left|x_{0}(k)-x_{i}(k)\right|+\zeta \max _{i} \max _{k}\left|x_{0}(k)-x_{i}(k)\right|}{\left|x_{0}(k)-x_{i}(k)\right|+\zeta \max _{i} \max _{k}\left|x_{0}(k)-x_{i}(k)\right|},
\end{aligned}
$$

where $\left|x_{0}(k)-x_{i}(k)\right|=\Delta_{i}(k)$ and $\zeta$ is the distinguished coefficient.

\section{The IF Decision-Making Method Based on Case-Based Reasoning}

3.1. The Main Idea of Case-Based Reasoning. An MCDM problem is described as follows. Suppose that a finite set of alternatives $X=\left\{X_{1}, X_{2}, \ldots, X_{m}\right\}$ is to be assessed with respect to a set of criteria $I=\left\{I_{1}, I_{2}, \ldots, I_{n}\right\}$. The consequence of alternative $X_{i}$ on criterion $I_{j}$ is represented as $c_{j}\left(X_{i}\right)$, abbreviated to $c_{j}^{i}$ for convenience.

Obviously, obtaining the DMs preferences is vital to any MCDM problem. Values and weights are two very important preferences concerning consequences and criteria, respectively. Values are the perception of DMs for the consequence data, which mirror the DMs' needs and objectives. Assume that the DMs' evaluation of alternative $X_{i}$ on criterion $I_{j}$ is written as $v_{j}^{i}=f_{j}\left(c_{j}^{i}\right)$, where $c_{j}^{i}$ is the consequence of alternative $X_{i}$ on criterion $I_{j}$, and the mapping $f_{j}(\cdot)$ corresponds to the DM's objectives. Suppose the criteria weight vector is denoted as $w=\left(w_{1}, w_{2}, \ldots, w_{n}\right)$, where $0 \leq w_{j} \leq 1$, and $\sum_{j=1}^{n} w_{j}=1$. Then the evaluation of alternative $X_{i}$ is expressed as

$$
V\left(X_{i}\right)=F\left(v_{j}^{i}, w\right),
$$

where $F(\cdot, \cdot)$ is a real-valued mapping from the preference vector $v\left(X_{i}\right)=\left(v_{1}^{i}, v_{2}^{i}, \ldots, v_{n}^{i}\right)$ and $w$ to the evaluation result. A typical linear value function can be written as

$$
V\left(X_{i}\right)=\sum_{j=1}^{n} w_{j} v_{j}^{i} .
$$

The main difficulty of MCDM lies in obtaining the DMs preference information on the criteria weights or values. Case-based reasoning (CBR) is an effective method for acquiring preferential information based on a test set of cases, which may include (1) DMs' past decisions, (2) decisions taken for a limited set of fictitious but realistic alternatives, and (3) decisions rendered for a representative subset of the alternatives, which are easy to evaluate and are very familiar to DMs. follows

The process of CBR method can be summarized as

(1) According to the (original) decision-making problem, a similar test problem should be given to DM. Assume a test set of alternatives $A=\left\{A_{1}, A_{2}, \ldots, A_{l}\right\}$. The alternatives may be obtained by having the DM modify historical records or fabricated by the DMs.

(2) On the basis of case base or DM's judgement, the alternatives in the test problem are clustered into $q$ categories $V_{1}, V_{2}, \ldots, V_{q}$ such that $V_{i}=$ $\left\{A_{i 1}, A_{i 2}, \ldots, A_{i n_{i}}\right\}$; here $A_{i j}$ are alternatives in category $V_{i}$. We assume a prioritization between these categories $V_{1}>V_{2}>\cdots>V_{q}$. The alternatives in the category $V_{i}$ have a higher priority than those in $V_{k}$ if $i<k$.

(3) Based on a mathematical programming model, we can estimate the most descriptive criterion weights $w_{i}$ and the grey relation coefficient thresholds $R_{1}, R_{2}, \ldots, R_{q-1}$. Assume $R_{1} \geq R_{2} \geq \cdots \geq R_{q-1} \geq 0$; then the grey relation coefficients of $A_{i k_{i}}$ to the centre $A^{*}$ are greater than or equal to $R_{i}$ but less than $R_{i-1}$.

(4) According to the most descriptive criterion weights and grey relation coefficients, calculate the comprehensive value of the alternatives in original decisionmaking problem.

The main idea of CBR method is captured in Figure 2.

Traditional CBR method [27] can only solve the decisionmaking problems for real number information with distance measure. Our CBR method uses grey incidence analysis rather than distance measure and can deal with decisionmaking problems for IFNs. Grey incidence analysis is a method to curve both the similarity and accessibility. 


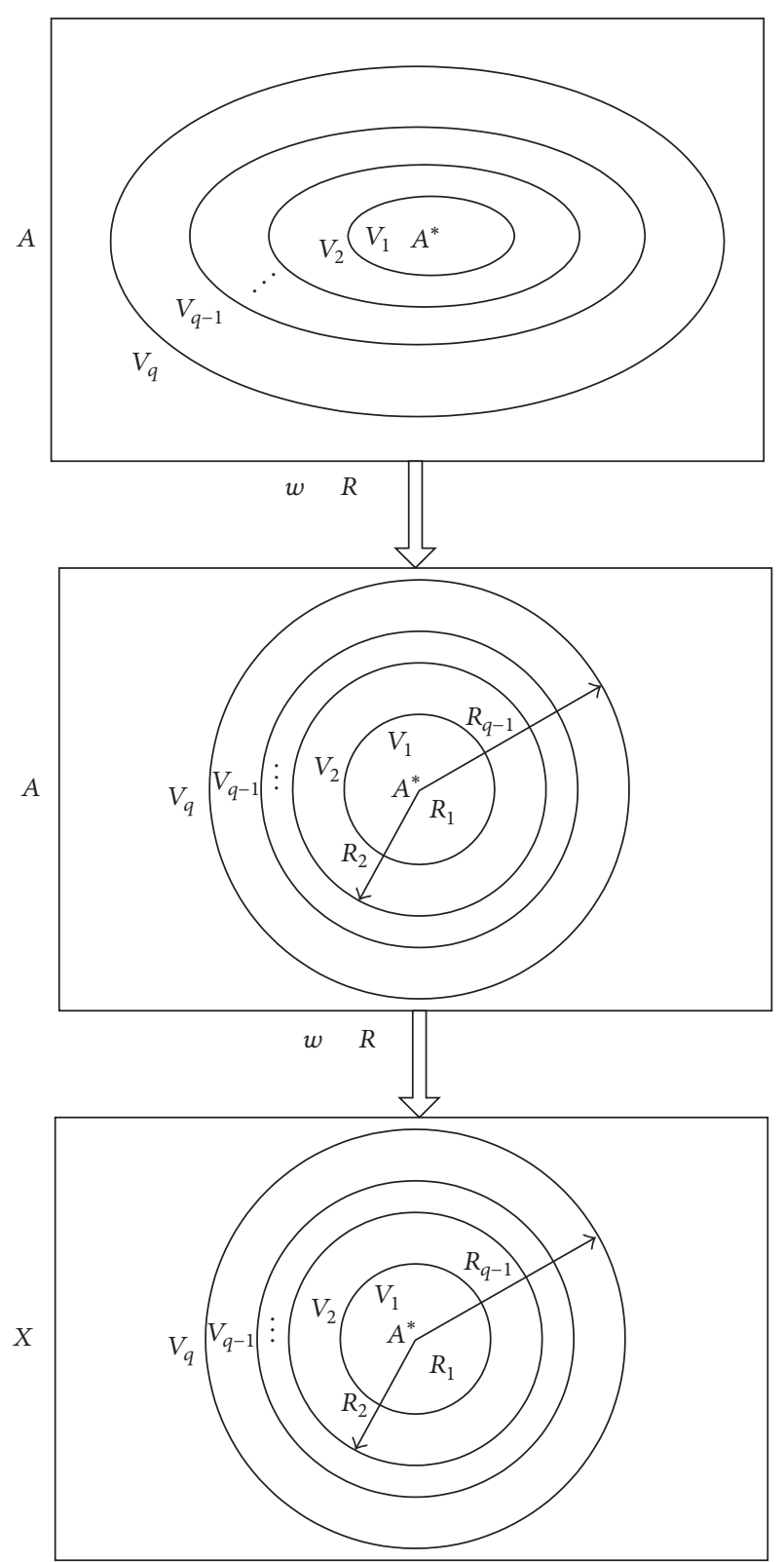

FIgURE 2: The main idea of CBR method.

Our CBR method can not only generate criterion weights $w$ and grey relation coefficients $R_{1}, R_{2}, \ldots, R_{q-1}$ but also afford accurate information in most instances by utilizing the DMs assessment of a case set. Another advantage lies in avoiding the difficulties of directly obtaining preference information such as criterion weights.

3.2. CBR Model for IFS Based on Prospect Theory. With MCDM problems, because of the uncertainties of the future, DMs tend to face a variety of natural states $Z=$ $\left\{Z_{1}, \ldots, Z_{s}, \ldots, Z_{k}\right\}$. Suppose that the probability of natural state $Z_{s}$ is $p_{s}$. In the natural state $Z_{s}$, the characteristic of the alternative $X_{i}$ with respect to criteria $I_{j}$ is represented as an
IFN $d^{s}{ }_{i j}(i=\{1,2, \ldots, m\}, j=\{1,2, \ldots, n\})$. The decisionmaking matrices in the different natural states given by $\mathrm{DMs}$ can be written as $D_{1}=\left(d^{1}{ }_{i j}\right)_{m \times n}, D_{2}=\left(d^{2}{ }_{i j}\right)_{m \times n}, \ldots, D_{k}=$ $\left(d^{k}{ }_{i j}\right)_{m \times n}$. For convenience, we call it the original decisionmaking problem.

According to the data of historically successful decisionmaking cases, the DM gives $k$ test decision-making matrices in the different natural states written as $T_{1}=\left[t^{1}{ }_{i j}\right]_{l \times n}, T_{2}=$ $\left[t^{2}{ }_{i j}\right]_{l \times n}, \ldots, T_{k}=\left[t^{k}{ }_{i j}\right]_{l \times n}$, where $t^{s}{ }_{i j}$ is an IFN value for alternative $A_{i}$ in terms of criterion $I_{j}$ in natural state $Z_{s}(i=$ $\{1,2, \ldots, l\}, j=\{1,2, \ldots, n\})$. Similarly, we call it the test decision-making problem.

Suppose that the DMs specify the alternatives set $A=$ $\left\{A_{1}, A_{2}, \ldots, A_{l}\right\}$ into $q$ categories $V_{1}, V_{2}, \ldots, V_{q}$ according to $k$ decision-making matrices $T_{1}=\left[t^{1}{ }_{i j}\right]_{l \times n}, T_{2}=\left[t^{2}{ }_{i j}\right]_{l \times n}, \ldots$, $T_{k}=\left[t^{k}{ }_{i j}\right]_{l \times n}$, where $V_{i}=\left\{A_{i_{1}}, A_{i_{2}}, \ldots, A_{i_{k_{i}}}\right\}$. For any $A_{i_{s}} \in V_{i}$, $A_{i-1_{k}} \in V_{i-1}$, we have $A_{i-1_{k}}>A_{i_{s}}$.

Due to the existence of bounded rationality, the DM used the PT while specifying the alternatives into the corresponding categories. Limited by the IFS algorithm rules, the prospect theory (PT) is hardly used in IFS environments directly. Therefore, translate the test IFN decision-making matrices $T_{1}=\left[t^{1}{ }_{i j}\right]_{l \times n}, T_{2}=\left[t^{2}{ }_{i j}\right]_{l \times n}, \ldots, T_{k}=\left[t^{k}{ }_{i j}\right]_{l \times n}$ into score decision-making matrices $S_{1}=\left[s^{1}{ }_{i j}\right]_{l \times n}, S_{2}=\left[s^{2}{ }_{i j}\right]_{l \times n}$, $\ldots, S_{k}=\left[s^{k}{ }_{i j}\right]_{l \times n}$ with new score function.

According to (7), transform the score decision-making matrices $S_{1}=\left[s^{1}{ }_{i j}\right]_{l \times n}, S_{2}=\left[s^{2}{ }_{i j}\right]_{l \times n}, \ldots, S_{k}=\left[s^{k}{ }_{i j}\right]_{l \times n}$ to prospect value decision-making matrix $W=\left[W_{i j}\right]_{l \times n}$. Here we suppose that all reference points are equal to zero according to the properties of IFNs. As a result, we can obtain

$$
W_{i j}=\sum_{s=1}^{k} h\left(p_{s}\right) c\left(s_{i j}^{s}\right)
$$

where

$$
\begin{aligned}
& h\left(p_{s}\right)=\frac{p_{s}^{\gamma}}{\left(p_{s}^{\gamma}+\left(1-p_{s}\right)^{\gamma}\right)^{1 / \gamma},} \\
& c\left(s_{i j}^{s}\right)= \begin{cases}s_{i j}^{s}, & s_{i j}^{s} \geq 0, \\
-\sigma\left(-s_{i j}^{s}\right)^{\beta}, & s_{i j}^{s}<0 .\end{cases}
\end{aligned}
$$

Suppose that $A^{*}$ is the best alternative in $V_{1} \cdot A^{*}$ is deemed to be a fictitious alternative at the centre of $A$. There are two ways to obtain $A^{*}$. The first way is that the DM can propose the best alternative according to his/her experiences. The second is taking the average of all of the alternatives in $V_{1}$ by using IFWA operator (see (1)).

Assume $A^{*}=\left[W_{* 1}, W_{* 2}, \ldots, W_{* n}\right]$. For any alternative $A_{k}=\left[W_{k 1}, W_{k 2}, \ldots, W_{k n}\right]$, we can obtain the grey incidence degree between $A^{*}$ and $A_{k}$ by (10) as follows:

$$
r\left(A^{*}, A_{k}\right)=\sum_{j=1}^{n} w_{j} r\left(W_{* j}, W_{k j}\right),
$$


where $w_{j}$ represents the relative importance for the criterion $I_{j}$.

The preceding grey relation coefficients of $A_{i i_{s}} \in V_{i}$ to the centre $A^{*}$ are greater than or equal to $R_{i}$ but less than $R_{i-1}$. Thus, assume $R_{0}=1, R_{q}=0$; we have $\sum_{j=1}^{n} w_{j} r\left(W_{* j}, W_{i i_{s} j}\right)+$ $\alpha_{i i_{s}}>R_{i}$. Here $0 \leq \alpha_{i i_{s}} \leq 1$ is an error adjustment parameter for the DMs inconsistent judgement on $A_{i i_{s}} \in V_{i}$. Also, we have $\sum_{j=1}^{n} w_{j} r\left(W_{* j}, W_{i i_{s} j}\right)-\beta_{i i_{s}}>R_{i}$. Again $0 \leq \beta_{i i_{s}} \leq 1$ is an error adjustment parameter for the DMs inconsistent judgement on $A_{i i_{s}} \in V_{i}$.

The following optimization model can be applied to obtain the most descriptive weight set $w$ and the appropriate grey relation coefficient thresholds $R_{1}, R_{2}, \ldots, R_{q-1}$ (assume $R=\left(R_{0}, R_{1}, \ldots, R_{q}\right)$, where $\left.R_{0}=1, R_{q}=0\right)$

$$
\begin{array}{ll}
\min & E R R=\sum_{i=1}^{q} \sum_{i_{s}=1}^{k_{i}} \alpha_{i i_{s}}^{2}+\beta_{i i_{s}}^{2} \\
\text { s.t. } & \sum_{j=1}^{n} w_{j} r\left(W_{* j}, W_{i i_{s} j}\right)+\alpha_{i i_{s}}>R_{i} \\
& \sum_{j=1}^{n} w_{j} r\left(W_{* j}, W_{i i_{s} j}\right)-\beta_{i i_{s}}>R_{i} \\
& w_{k} \geq 0, \\
& \sum_{k=1}^{n} w_{k}=1, \\
& R_{1} \geq R_{2} \geq \cdots \geq R_{q-1} \geq 0 \\
& 0 \leq \alpha_{i i_{s}}, \beta_{i i_{s}} \leq 1, \\
& i=1,2, \ldots, q, \\
& i_{s}=1,2, \ldots, k_{i} .
\end{array}
$$

Theorem 8. Mathematical programming (P1) has at least one optimal solution $w^{*}$ and $R^{*}$.

Proof. The constraints in (P1) constitute a convex set. The objective function $E R R=\sum_{i=1}^{q} \sum_{i_{s}=1}^{k_{i}} \alpha_{i i_{s}}^{2}+\beta_{i i_{s}}^{2}$ is a quadratic function on this set. As all of the variables are continuous and bounded, (P1) attains its maximum at least once. From the above analysis, the weight set $w$ and the appropriate grey relation coefficient thresholds $R_{1}, R_{2}, \ldots, R_{q-1}$ can be gained.

Next we will discuss the method for solving the original decision-making problem. In fact, the above analysis supposes that the DMs are bounded rational and they utilize the PT to case-based reasoning. In fact, PT is a very useful tool to explain why DMs are bounded rational. However, PT may be not a perfect method for directing people to make a reasonable decision. For example, the PT can explain why most people want to buy lottery tickets. If we use PT, we may come to the conclusion that the prospect value of buying lottery tickets is greater than that of paying money to buy lottery tickets. It is for this reason that the people who bought lottery tickets overestimate the probability of winning the lottery. In fact, on the individualist side, the lottery ticket is not worth buying. Hence, we will use traditional expected utility functions to aggregate the decision-making information of the original decision-making problem in all of its natural states and compute the grey incidence value between the best alternative $A^{*}$ and all the alternatives. We then categorize all the alternatives in the original problem according to the grey incidence value and threshold value.

As mentioned previously, we firstly aggregate the decision-making matrices $D_{1}=\left(d^{1}{ }_{i j}\right)_{m \times n}, D_{2}=\left(d^{2}{ }_{i j}\right)_{m \times n}$, $\ldots, D_{k}=\left(d^{k}{ }_{i j}\right)_{m \times n}$ into expectation matrix $D=\left(d_{i j}\right)_{m \times n}$ :

$$
d_{i j}=\sum_{s=1}^{k} p_{s} d_{i j}^{s}
$$

where $d_{i j}$ is an IFN.

We then aggregate the alternative $A^{*}$ by calculating the expected values in different natural states. For convenience, we assume the expected value vector of $A^{*}$ is denoted by $E\left(A^{*}\right)=\left(A_{1}^{*}, A_{2}^{*}, \ldots, A_{n}^{*}\right)$.

Transform the IFN matrix $D=\left(d_{i j}\right)_{m \times n}$ and the vector $E\left(A^{*}\right)=\left(A_{1}^{*}, A_{2}^{*}, \ldots, A_{n}^{*}\right)$ into the real number matrix $D^{\prime}=$ $\left(d_{i j}^{\prime}\right)_{m \times n}$ and the vector $E\left(A^{*}\right)^{\prime}=\left(A_{1}^{* \prime}, A_{2}^{* \prime}, \ldots, A_{n}^{* \prime}\right)$ by the score function in (5).

According to the most descriptive weight set $w^{*}=\left(w_{1}^{*}\right.$, $\left.w_{2}^{*}, \ldots, w_{n}^{*}\right)$ obtained by (P1), calculate the grey incidence degree between alternatives $X_{i}$ and $A^{*}$ as follows:

$$
r\left(A^{*}, X_{i}\right)=\sum_{j=1}^{n} w_{j} r\left(A_{j}^{* \prime}, d_{i j}^{\prime}\right) .
$$

Using the threshold value $R_{1}, R_{2}, \ldots, R_{q-1}$ and the grey incidence degree $r\left(A^{*}, X_{i}\right)$, we categorize the alternatives $X_{i}$ $(i=1,2, \ldots, m)$. If $R_{k} \leq r\left(A^{*}, X_{i}\right) \leq R_{k-1}(k=1,2, \ldots, q)$, then the alternative $X_{i}$ is in category $V_{k}$.

Based on the above analysis, the decision-making process and algorithm are summarized as follows.

Step 1. DM establishes his/her decision-making matrices in the $k$ different natural states with IFNs: $D_{1}=\left(d^{1}{ }_{i j}\right)_{m \times n}, D_{2}=$ $\left(d^{2}{ }_{i j}\right)_{m \times n}, \ldots, D_{k}=\left(d^{k}{ }_{i j}\right)_{m \times n}$, and the probability of natural state $Z_{s}: p\left(Z_{s}\right), s=1,2, \ldots, k$.

Step 2. Identify $k$ test decision-making matrices in the different natural states for the alternatives $A=\left\{A_{1}, A_{2}, \ldots, A_{l}\right\}$, $T_{1}=\left[t^{1}{ }_{i j}\right]_{l \times n}, T_{2}=\left[t^{2}{ }_{i j}\right]_{l \times n}, \ldots, T_{k}=\left[t^{k}{ }_{i j}\right]_{l \times n}$, and ask the DM to specify the alternatives into the corresponding $q$ categories $V_{1}, V_{2}, \ldots, V_{q}$.

Step 3. Find the best alternative $A^{*}$ according to DM's experiences or average value of elements in $V_{1}$. 
Step 4. Convert the IF decision-making matrices $T_{1}=$ $\left[t^{1}{ }_{i j}\right]_{l \times n}, T_{2}=\left[t^{2}{ }_{i j}\right]_{l \times n}, \ldots, T_{k}=\left[t^{k}{ }_{i j}\right]_{l \times n}$ into score decisionmaking matrices $S_{1}=\left[s^{1}{ }_{i j}\right]_{l \times n}, S_{2}=\left[s^{2}{ }_{i j}\right]_{l \times n}, \ldots, S_{k}=\left[s^{k}{ }_{i j}\right]_{l \times n}$ according to (5).

Step 5. Integrate all the score decision-making matrices $S_{1}=$ $\left[s^{1}{ }_{i j}\right]_{l \times n}, S_{2}=\left[s^{2}{ }_{i j}\right]_{l \times n}, \ldots, S_{k}=\left[s^{k}{ }_{i j}\right]_{l \times n}$ into the prospect value matrix $W=\left[W_{i j}\right]_{l \times n}$ using (13).

Step 6. Apply the optimization model (P1) to get $w^{*}$ and the threshold value $R_{1}, R_{2}, \ldots, R_{q-1}$.

Step 7. Integrate all the IFN decision-making matrices in original decision-making problem, $D_{1}=\left(d^{1}{ }_{i j}\right)_{m \times n}, D_{2}=$ $\left(d^{2}{ }_{i j}\right)_{m \times n}, \ldots, D_{k}=\left(d^{k}{ }_{i j}\right)_{m \times n}$ into expectation matrix $D=$ $\left(d_{i j}\right)_{m \times n}$ by (16). Meanwhile, aggregate the alternative $A^{*}$ in different natural states with expectancy theory: $E\left(A^{*}\right)=\left(A_{1}^{*}\right.$, $\left.A_{2}^{*}, \ldots, A_{n}^{*}\right)$.

Step 8. Transform the IFN matrix $D=\left(d_{i j}\right)_{m \times n}$ and the value vector $E\left(A^{*}\right)=\left(A_{1}^{*}, A_{2}^{*}, \ldots, A_{n}^{*}\right)$ into real number matrix $D^{\prime}=\left(d_{i j}^{\prime}\right)_{m \times n}$ and value vector $E\left(A^{*}\right)^{\prime}=\left(A_{1}^{* \prime}, A_{2}^{* \prime}, \ldots, A_{n}^{* \prime}\right)$ by (5).

Step 9. Calculate the grey incidence degree $(\xi=0.5)$ between alternatives $X_{i}$ and $A^{*}$ with (17). Then compare the threshold value $R_{1}, R_{2}, \ldots, R_{q-1}$ and $r\left(A^{*}, X_{i}\right)$. If $R_{k} \leq r\left(A^{*}, X_{i}\right) \leq R_{k-1}$ $(k=1,2, \ldots, q)$, then the alternative $X_{i}$ is in category $V_{k}$. Rank the alternatives based on $r\left(A^{*}, X_{i}\right)$.

\section{Case Study}

In this section, two examples are studied to show the applicability and validation of the proposed method.

4.1. An Example for Investing in an R\&D Project. A venture capital company wants to invest in an $R \& D$ project. There are four potential R\&D projects $X_{1}, X_{2}, X_{3}, X_{4}$ for further evaluation. The company invites one expert to evaluate these four projects based on four factors: organizing ability $\left(I_{1}\right)$, credit quality $\left(I_{2}\right)$, research ability $\left(I_{3}\right)$, and profitability $\left(I_{4}\right)$. There are three possible economic environments: fast-developing $\left(Z_{1}\right)$, low-developing $\left(Z_{2}\right)$, and economic setbacks $\left(Z_{3}\right)$.

The expert estimates the probabilities for the above three situations: $p\left(Z_{1}\right)=0.6, p\left(Z_{2}\right)=0.3$, and $p\left(Z_{3}\right)=0.1$.

\subsubsection{The Decision-Making Process Based on the Proposed Method}

Step 1. DM establishes his/her decision-making matrices $D_{1}$, $D_{2}$, and $D_{3}$ in the three different natural states with IFNs in Tables 1-3.

Step 2. Identify three test decision-making matrices $T_{1}, T_{2}$, and $T_{3}$ in the different natural states for eight alternatives in Tables 4-6.
TABLE 1: Decision-making matrix $D_{1}$ in natural state fast-developing $\left(Z_{1}\right)\left(p\left(Z_{1}\right)=0.6\right)$

\begin{tabular}{ccccc}
\hline & $I_{1}$ & $I_{2}$ & $I_{3}$ & $I_{4}$ \\
\hline$X_{1}$ & $\langle 0.3,0.5\rangle$ & $\langle 0.6,0.3\rangle$ & $\langle 0.5,0.4\rangle$ & $\langle 0.7,0.1\rangle$ \\
$X_{2}$ & $\langle 0.5,0.4\rangle$ & $\langle 0.4,0.4\rangle$ & $\langle 0.6,0.2\rangle$ & $\langle 0.6,0.3\rangle$ \\
$X_{3}$ & $\langle 0.8,0.1\rangle$ & $\langle 0.2,0.4\rangle$ & $\langle 0.5,0.3\rangle$ & $\langle 0.6,0.2\rangle$ \\
$X_{4}$ & $\langle 0.6,0.3\rangle$ & $\langle 0.5,0.4\rangle$ & $\langle 0.5,0.4\rangle$ & $\langle 0.4,0.5\rangle$ \\
\hline
\end{tabular}

TABLE 2: Decision-making matrix $D_{2}$ in natural state lowdeveloping $\left(Z_{2}\right)\left(p\left(Z_{2}\right)=0.3\right)$.

\begin{tabular}{ccccc}
\hline & $I_{1}$ & $I_{2}$ & $I_{3}$ & $I_{4}$ \\
\hline$X_{1}$ & $\langle 0.5,0.3\rangle$ & $\langle 0.4,0.5\rangle$ & $\langle 0.6,0.2\rangle$ & $\langle 0.6,0.1\rangle$ \\
$X_{2}$ & $\langle 0.5,0.4\rangle$ & $\langle 0.6,0.3\rangle$ & $\langle 0.5,0.2\rangle$ & $\langle 0.5,0.3\rangle$ \\
$X_{3}$ & $\langle 0.7,0.1\rangle$ & $\langle 0.3,0.4\rangle$ & $\langle 0.5,0.3\rangle$ & $\langle 0.4,0.2\rangle$ \\
$X_{4}$ & $\langle 0.5,0.3\rangle$ & $\langle 0.4,0.3\rangle$ & $\langle 0.6,0.2\rangle$ & $\langle 0.6,0.3\rangle$ \\
\hline
\end{tabular}

TABLE 3: Decision-making matrix $D_{3}$ in natural state economic setbacks $\left(Z_{3}\right)\left(p\left(Z_{3}\right)=0.1\right)$.

\begin{tabular}{ccccc}
\hline & $I_{1}$ & $I_{2}$ & $I_{3}$ & $I_{4}$ \\
\hline$X_{1}$ & $\langle 0.7,0.1\rangle$ & $\langle 0.4,0.5\rangle$ & $\langle 0.5,0.2\rangle$ & $\langle 0.6,0.2\rangle$ \\
$X_{2}$ & $\langle 0.4,0.4\rangle$ & $\langle 0.7,0.2\rangle$ & $\langle 0.5,0.3\rangle$ & $\langle 0.6,0.3\rangle$ \\
$X_{3}$ & $\langle 0.6,0.1\rangle$ & $\langle 0.5,0.4\rangle$ & $\langle 0.5,0.3\rangle$ & $\langle 0.6,0.1\rangle$ \\
$X_{4}$ & $\langle 0.6,0.3\rangle$ & $\langle 0.3,0.3\rangle$ & $\langle 0.7,0.2\rangle$ & $\langle 0.4,0.3\rangle$ \\
\hline
\end{tabular}

TABLE 4: Test decision-making matrix $T_{1}$ in natural state fastdeveloping $\left(Z_{1}\right)\left(p\left(Z_{1}\right)=0.6\right)$.

\begin{tabular}{ccccc}
\hline & $I_{1}$ & $I_{2}$ & $I_{3}$ & $I_{4}$ \\
\hline$A_{1}$ & $\langle 0.6,0.3\rangle$ & $\langle 0.4,0.2\rangle$ & $\langle 0.6,0.2\rangle$ & $\langle 0.6,0.1\rangle$ \\
$A_{2}$ & $\langle 0.3,0.4\rangle$ & $\langle 0.6,0.3\rangle$ & $\langle 0.7,0.2\rangle$ & $\langle 0.6,0.3\rangle$ \\
$A_{3}$ & $\langle 0.7,0.1\rangle$ & $\langle 0.3,0.4\rangle$ & $\langle 0.2,0.3\rangle$ & $\langle 0.4,0.2\rangle$ \\
$A_{4}$ & $\langle 0.7,0.3\rangle$ & $\langle 0.4,0.3\rangle$ & $\langle 0.6,0.2\rangle$ & $\langle 0.6,0.3\rangle$ \\
$A_{5}$ & $\langle 0.7,0.1\rangle$ & $\langle 0.4,0.3\rangle$ & $\langle 0.6,0.2\rangle$ & $\langle 0.6,0.2\rangle$ \\
$A_{6}$ & $\langle 0.4,0.4\rangle$ & $\langle 0.7,0.2\rangle$ & $\langle 0.6,0.3\rangle$ & $\langle 0.6,0.3\rangle$ \\
$A_{7}$ & $\langle 0.6,0.1\rangle$ & $\langle 0.3,0.4\rangle$ & $\langle 0.4,0.3\rangle$ & $\langle 0.6,0.1\rangle$ \\
$A_{8}$ & $\langle 0.6,0.3\rangle$ & $\langle 0.3,0.3\rangle$ & $\langle 0.7,0.2\rangle$ & $\langle 0.4,0.3\rangle$ \\
\hline & & & &
\end{tabular}

TABLE 5: Test decision-making matrix $T_{2}$ in natural state lowdeveloping $\left(Z_{2}\right)\left(p\left(Z_{2}\right)=0.3\right)$.

\begin{tabular}{ccccc}
\hline & $I_{1}$ & $I_{2}$ & $I_{3}$ & $I_{4}$ \\
\hline$A_{1}$ & $\langle 0.4,0.3\rangle$ & $\langle 0.5,0.2\rangle$ & $\langle 0.5,0.3\rangle$ & $\langle 0.6,0.2\rangle$ \\
$A_{2}$ & $\langle 0.5,0.4\rangle$ & $\langle 0.4,0.3\rangle$ & $\langle 0.4,0.3\rangle$ & $\langle 0.6,0.3\rangle$ \\
$A_{3}$ & $\langle 0.6,0.1\rangle$ & $\langle 0.5,0.4\rangle$ & $\langle 0.6,0.3\rangle$ & $\langle 0.6,0.1\rangle$ \\
$A_{4}$ & $\langle 0.5,0.3\rangle$ & $\langle 0.4,0.3\rangle$ & $\langle 0.5,0.1\rangle$ & $\langle 0.6,0.3\rangle$ \\
$A_{5}$ & $\langle 0.6,0.2\rangle$ & $\langle 0.5,0.3\rangle$ & $\langle 0.7,0.2\rangle$ & $\langle 0.6,0.2\rangle$ \\
$A_{6}$ & $\langle 0.6,0.3\rangle$ & $\langle 0.7,0.2\rangle$ & $\langle 0.4,0.3\rangle$ & $\langle 0.5,0.3\rangle$ \\
$A_{7}$ & $\langle 0.6,0.2\rangle$ & $\langle 0.5,0.4\rangle$ & $\langle 0.4,0.3\rangle$ & $\langle 0.6,0.3\rangle$ \\
$A_{8}$ & $\langle 0.5,0.3\rangle$ & $\langle 0.7,0.3\rangle$ & $\langle 0.7,0.2\rangle$ & $\langle 0.6,0.3\rangle$ \\
\hline
\end{tabular}


TABLE 6: Test decision-making matrix $T_{3}$ in natural state economic setbacks $\left(Z_{3}\right)\left(p\left(Z_{3}\right)=0.1\right)$.

\begin{tabular}{ccccc}
\hline & $I_{1}$ & $I_{2}$ & $I_{3}$ & $I_{4}$ \\
\hline$A_{1}$ & $\langle 0.5,0.2\rangle$ & $\langle 0.6,0.3\rangle$ & $\langle 0.6,0.2\rangle$ & $\langle 0.5,0.1\rangle$ \\
$A_{2}$ & $\langle 0.5,0.1\rangle$ & $\langle 0.7,0.1\rangle$ & $\langle 0.7,0.2\rangle$ & $\langle 0.5,0.4\rangle$ \\
$A_{3}$ & $\langle 0.7,0.2\rangle$ & $\langle 0.5,0.3\rangle$ & $\langle 0.6,0.3\rangle$ & $\langle 0.4,0.2\rangle$ \\
$A_{4}$ & $\langle 0.7,0.1\rangle$ & $\langle 0.5,0.3\rangle$ & $\langle 0.6,0.1\rangle$ & $\langle 0.6,0.3\rangle$ \\
$A_{5}$ & $\langle 0.7,0.2\rangle$ & $\langle 0.4,0.3\rangle$ & $\langle 0.6,0.3\rangle$ & $\langle 0.5,0.2\rangle$ \\
$A_{6}$ & $\langle 0.5,0.1\rangle$ & $\langle 0.6,0.2\rangle$ & $\langle 0.6,0.3\rangle$ & $\langle 0.6,0.1\rangle$ \\
$A_{7}$ & $\langle 0.6,0.2\rangle$ & $\langle 0.5,0.4\rangle$ & $\langle 0.5,0.3\rangle$ & $\langle 0.6,0.2\rangle$ \\
$A_{8}$ & $\langle 0.6,0.2\rangle$ & $\langle 0.5,0.3\rangle$ & $\langle 0.7,0.1\rangle$ & $\langle 0.5,0.3\rangle$ \\
\hline
\end{tabular}

TABLE 7: Score matrix $S_{1}$.

\begin{tabular}{ccccc}
\hline & $I_{1}$ & $I_{2}$ & $I_{3}$ & $I_{4}$ \\
\hline$A_{1}$ & 0.29 & 0.27 & 0.43 & 0.63 \\
$A_{2}$ & -0.25 & 0.32 & 0.52 & 0.29 \\
$A_{3}$ & 0.7 & -0.19 & -0.37 & 0.16 \\
$A_{4}$ & 0.4 & 0.09 & 0.43 & 0.29 \\
$A_{5}$ & 0.7 & 0.09 & 0.43 & 0.42 \\
$A_{6}$ & -0.08 & 0.54 & 0.29 & 0.29 \\
$A_{7}$ & 0.63 & -0.19 & 0.02 & 0.63 \\
$A_{8}$ & 0.29 & -0.07 & 0.52 & 0.01 \\
\hline
\end{tabular}

TABLE 8: Score matrix $S_{2}$.

\begin{tabular}{lcccc}
\hline & $I_{1}$ & $I_{2}$ & $I_{3}$ & $I_{4}$ \\
\hline$A_{1}$ & 0.04 & 0.35 & 0.18 & 0.43 \\
$A_{2}$ & 0.08 & 0.06 & 0.03 & 0.17 \\
$A_{3}$ & 0.65 & 0.08 & 0.3 & 0.63 \\
$A_{4}$ & 0.18 & 0.06 & 0.56 & 0.29 \\
$A_{5}$ & 0.44 & 0.2 & 0.52 & 0.43 \\
$A_{6}$ & 0.3 & 0.53 & 0.03 & 0.17 \\
$A_{7}$ & 0.44 & 0.08 & 0.03 & 0.29 \\
$A_{8}$ & 0.18 & 0.4 & 0.53 & 0.29 \\
\hline
\end{tabular}

Then, ask the DM to specify the alternatives into the corresponding three categories: $V_{1}=\left\{A_{4}, A_{5}\right\}, V_{2}=\left\{A_{1}\right.$, $\left.A_{3}, A_{7}, A_{8}\right\}$, and $V_{3}=\left\{A_{2}, A_{6}\right\}$, where $V_{1}, V_{2}$, and $V_{3}$ mean "good," "acceptable," and "poor," respectively.

Step 3. The expert finds the best alternative $A^{*}=A_{5}$.

Step 4. According to (5), convert the IF decision-making matrices $T_{1}, T_{2}$, and $T_{3}$ into score matrices $S_{1}, S_{2}$, and $S_{3}$, respectively, as shown in Tables 7-9.

Step 5. Integrate all the score decision-making matrices $S_{1}$, $S_{2}$, and $S_{3}$ into the prospect value matrix $W$ by (13), as shown in Table 10.

Step 6. By using the program (P1), we get the most descriptive weight $w^{*}=(0.4,0.37,0.12,0.11)$ and the thresholds $R_{1}=0.72, R_{2}=0.52$.
TABLe 9: Score matrix $S_{3}$.

\begin{tabular}{lcccc}
\hline & $I_{1}$ & $I_{2}$ & $I_{3}$ & $I_{4}$ \\
\hline$A_{1}$ & 0.24 & 0.3 & 0.41 & 0.55 \\
$A_{2}$ & 0.46 & 0.71 & 0.51 & 0.07 \\
$A_{3}$ & 0.5 & 0.18 & 0.29 & 0.17 \\
$A_{4}$ & 0.66 & 0.18 & 0.61 & 0.29 \\
$A_{5}$ & 0.5 & 0.04 & 0.29 & 0.31 \\
$A_{6}$ & 0.46 & 0.44 & 0.29 & 0.63 \\
$A_{7}$ & 0.38 & 0.08 & 0.15 & 0.43 \\
$A_{8}$ & 0.39 & 0.18 & 0.69 & 0.17 \\
\hline
\end{tabular}

TABLe 10: Prospect value matrix $W$.

\begin{tabular}{lcccc}
\hline & $I_{1}$ & $I_{2}$ & $I_{3}$ & $I_{4}$ \\
\hline$A_{1}$ & 0.23 & 0.34 & 0.38 & 0.58 \\
$A_{2}$ & -0.19 & 0.34 & 0.39 & 0.24 \\
$A_{3}$ & 0.67 & -0.17 & -0.27 & 0.35 \\
$A_{4}$ & 0.41 & 0.13 & 0.54 & 0.33 \\
$A_{5}$ & 0.6 & 0.14 & 0.47 & 0.44 \\
$A_{6}$ & 0.09 & 0.55 & 0.24 & 0.35 \\
$A_{7}$ & 0.55 & -0.19 & 0.07 & 0.51 \\
$A_{8}$ & 0.31 & 0.08 & 0.58 & 0.16 \\
\hline
\end{tabular}

TABLe 11: Expectation matrix $D$ and $A^{*}$.

\begin{tabular}{lcccc}
\hline & $I_{1}$ & $I_{2}$ & $I_{3}$ & $I_{4}$ \\
\hline$X_{1}$ & $\langle 0.42,0.37\rangle$ & $\langle 0.53,0.37\rangle$ & $\langle 0.53,0.3\rangle$ & $\langle 0.66,0.11\rangle$ \\
$X_{2}$ & $\langle 0.49,0.4\rangle$ & $\langle 0.5,0.34\rangle$ & $\langle 0.56,0.21\rangle$ & $\langle 0.57,0.3\rangle$ \\
$X_{3}$ & $\langle 0.76,0.1\rangle$ & $\langle 0.27,0.4\rangle$ & $\langle 0.5,0.3\rangle$ & $\langle 0.55,0.19\rangle$ \\
$X_{4}$ & $\langle 0.57,0.3\rangle$ & $\langle 0.45,0.36\rangle$ & $\langle 0.56,0.3\rangle$ & $\langle 0.47,0.41\rangle$ \\
\hline$E\left(A^{*}\right)$ & $\langle 0.67,0.13\rangle$ & $\langle 0.43,0.3\rangle$ & $\langle 0.63,0.21\rangle$ & $\langle 0.59,0.2\rangle$ \\
\hline
\end{tabular}

TABLE 12: Real number matrix $D^{\prime}$ and value vector $E\left(A^{*}\right)^{\prime}$.

\begin{tabular}{lcccc}
\hline & $I_{1}$ & $I_{2}$ & $I_{3}$ & $I_{4}$ \\
\hline$X_{1}$ & -0.02 & 0.17 & 0.21 & 0.66 \\
$X_{2}$ & 0.06 & 0.18 & 0.38 & 0.26 \\
$X_{3}$ & 0.74 & -0.23 & 0.18 & 0.39 \\
$X_{4}$ & 0.26 & 0.1 & 0.24 & 0.02 \\
\hline$E\left(A^{*}\right)$ & 0.62 & 0.15 & 0.45 & 0.41
\end{tabular}

Step 7. Integrate all the IFN decision-making matrices $D_{1}$, $D_{2}$, and $D_{3}$ in original decision-making problem and $A^{*}$ into expectation matrix $D$ and $E\left(A^{*}\right)$, respectively, as shown in Table 11.

Step 8. Transform the IFN matrix $D$ and $E\left(A^{*}\right)$ into real number information in Table 12. 
TABLE 13: Score decision-making matrix $S_{1}^{\prime}$.

\begin{tabular}{ccccc}
\hline & $I_{1}$ & $I_{2}$ & $I_{3}$ & $I_{4}$ \\
\hline$X_{1}$ & -0.295 & 0.328 & 0.087 & 0.708 \\
$X_{2}$ & 0.085 & -0.013 & 0.460 & 0.298 \\
$X_{3}$ & 0.765 & -0.355 & 0.199 & 0.436 \\
$X_{4}$ & 0.308 & 0.105 & 0.087 & -0.145 \\
\hline
\end{tabular}

TABLE 14: Score decision-making matrix $S_{2}^{\prime}$.

\begin{tabular}{lcccc}
\hline & $I_{1}$ & $I_{2}$ & $I_{3}$ & $I_{4}$ \\
\hline$X_{1}$ & 0.178 & -0.117 & 0.420 & 0.632 \\
$X_{2}$ & 0.077 & 0.328 & 0.303 & 0.167 \\
$X_{3}$ & 0.711 & -0.161 & 0.162 & 0.169 \\
$X_{4}$ & 0.178 & 0.124 & 0.290 & 0.292 \\
\hline
\end{tabular}

TABLE 15: Score decision-making matrix $S_{3}^{\prime}$.

\begin{tabular}{ccccc}
\hline & $I_{1}$ & $I_{2}$ & $I_{3}$ & $I_{4}$ \\
\hline$X_{1}$ & 0.693 & -0.126 & 0.319 & 0.420 \\
$X_{2}$ & -0.088 & 0.544 & 0.172 & 0.290 \\
$X_{3}$ & 0.621 & 0.096 & 0.172 & 0.626 \\
$X_{4}$ & 0.288 & -0.061 & 0.523 & 0.012 \\
\hline
\end{tabular}

TABLE 16: Prospect value matrix $W^{\prime}$.

\begin{tabular}{lcccc}
\hline & $I_{1}$ & $I_{2}$ & $I_{3}$ & $I_{4}$ \\
\hline$X_{1}$ & -0.160 & 0.001 & 0.272 & 0.650 \\
$X_{2}$ & 0.038 & 0.206 & 0.390 & 0.292 \\
$X_{3}$ & 0.733 & -0.549 & 0.218 & 0.418 \\
$X_{4}$ & 0.300 & 0.080 & 0.268 & -0.083 \\
\hline
\end{tabular}

Step 9. Calculate the grey incidence degree between alternatives $X_{i}(i=1,2,3,4)$ and $A^{*}$ with (17). We get

$$
\begin{aligned}
& r\left(X_{1}, A^{*}\right)=0.671, \\
& r\left(X_{2}, A^{*}\right)=0.648, \\
& r\left(X_{3}, A^{*}\right)=0.646, \\
& r\left(X_{4}, A^{*}\right)=0.738 .
\end{aligned}
$$

Since $R_{1}=0.72, R_{2}=0.52$, we can obtain that $X_{4} \in V_{1}$, $X_{1} \in V_{2}, X_{2} \in V_{2}$, and $X_{3} \in V_{2}$. That is, $X_{4}$ belongs to "good" and $X_{1}, X_{2}$, and $X_{3}$ belong to "acceptable."

4.1.2. Comparison with Li et al.s Method. To illustrate the superiority of our proposed method, we carry out a comparative analysis of the proposed method with the existing intuitionistic fuzzy stochastic multicriteria decision-making methods based on prospect theory [23]. The steps and results using the method in [23] are shown as follows.

Step 1. Convert the IF decision-making matrices $D_{1}, D_{2}$, and $D_{3}$ into score decision-making matrices $S_{1}^{\prime}, S_{2}^{\prime}$, and $S_{3}^{\prime}$, respectively, as shown in Tables 13-15.
Step 2. Integrate all the score decision-making matrices $S_{1}^{\prime}$, $S_{2}^{\prime}$, and $S_{3}^{\prime}$ into prospect value matrix $W^{\prime}$ using (13), as shown in Table 16.

Step 3. According to the prospect value matrix $W^{\prime}$, compute the mean vector $\bar{I}=(0.19,0.232,0.08,0.1)^{T}$. Based on $(10)$, the most descriptive weight set can be obtained as follows: $W^{* \prime}=(0.236,0.24,0.268,0.256)$.

Step 4. Calculate the overall values of alternatives according to the most descriptive weight set $W^{* \prime}$ :

$$
\begin{gathered}
Y^{\prime}\left(X_{1}\right)=0.202, \\
Y^{\prime}\left(X_{2}\right)=0.238, \\
Y^{\prime}\left(X_{3}\right)=0.207, \\
Y\left(X_{4}\right)=0.141 .
\end{gathered}
$$

Step 5. Rank the alternatives: $X_{2}>X_{3}>X_{1}>X_{4}$.

The rankings are different by the proposed method and $\mathrm{Li}$ et al's method [23]. The reason lies in the following points:

(1) The decision-making mechanisms are remarkably different. The former uses the PT as a decisionmaking mechanism to guide DMs to make a decision. As mentioned, PT is a good theory to explain why DMs usually make some incomprehensible decisions, while it is not a good theory to guide DMs to make a scientific one. The latter capitalizes on PT in test decision-making problems for reflecting DMs' bounded rationality to obtain criterion weights. We can then aggregate decision-making information by using the EU theory and rank the alternatives by the CBR method.

(2) The methods for obtaining criterion weights are different. The former mainly uses the GRA method without considering the preference and experience of DMs, while the latter utilizes the CBR method and considers not only decision-making data but also DM's preference and experience. In fact, DMs' subjective preference and experiences are very important for real decision-making problems. And they have a significant impact on the correctness of the decisionmaking. If a decision-making method considered decision-making matrices and ignored DMs' subjective preferences and experiences, its result could be misleading. The CBR method combines the decisionmaking matrices with DMs' subjective preferences and experiences and has the capability to make more reliable decisions.

4.2. An Example for Choosing Rescue Plans. In this example, we study an emergency rescue scenario for a flooding accident of a coal mine, which was previously considered in [42]. There are 5 rescue plans expressed as $X_{1}, X_{2}, X_{3}$, and $X_{4}$ for further evaluation. After experts' discussion, three criteria should be considered: personnel security $\left(I_{1}\right)$, rescue time 
TABLE 17: Decision-making matrix $D_{1}$ in situation $Z_{1}\left(P\left(Z_{1}\right)=0.3\right)$.

\begin{tabular}{cccc}
\hline & $I_{1}$ & $I_{2}$ & $I_{3}$ \\
\hline$X_{1}$ & $\langle 0.6,0.3\rangle$ & $\langle 0.5,0.2\rangle$ & $\langle 0.4,0.3\rangle$ \\
$X_{2}$ & $\langle 0.7,0.1\rangle$ & $\langle 0.5,0.4\rangle$ & $\langle 0.5,0.3\rangle$ \\
$X_{3}$ & $\langle 0.4,0.3\rangle$ & $\langle 0.5,0.2\rangle$ & $\langle 0.6,0.3\rangle$ \\
$X_{4}$ & $\langle 0.4,0.2\rangle$ & $\langle 0.5,0.3\rangle$ & $\langle 0.7,0.3\rangle$ \\
\hline
\end{tabular}

TABLE 18: Decision-making matrix $D_{2}$ in situation $Z_{2}\left(P\left(Z_{2}\right)=0.7\right)$.

\begin{tabular}{cccc}
\hline & $I_{1}$ & $I_{2}$ & $I_{3}$ \\
\hline$X_{1}$ & $\langle 0.5,0.4\rangle$ & $\langle 0.6,0.4\rangle$ & $\langle 0.4,0.3\rangle$ \\
$X_{2}$ & $\langle 0.6,0.2\rangle$ & $\langle 0.5,0.4\rangle$ & $\langle 0.5,0.3\rangle$ \\
$X_{3}$ & $\langle 0.6,0.3\rangle$ & $\langle 0.5,0.3\rangle$ & $\langle 0.6,0.3\rangle$ \\
$X_{4}$ & $\langle 0.5,0.2\rangle$ & $\langle 0.8,0.1\rangle$ & $\langle 0.6,0.2\rangle$ \\
\hline
\end{tabular}

TABLE 19: Test decision-making matrix $T_{1}$ in situation $Z_{1}$.

\begin{tabular}{lccc}
\hline & $I_{1}$ & $I_{2}$ & $I_{3}$ \\
\hline$A_{1}$ & $\langle 0.6,0.3\rangle$ & $\langle 0.7,0.2\rangle$ & $\langle 0.6,0.3\rangle$ \\
$A_{2}$ & $\langle 0.3,0.4\rangle$ & $\langle 0.2,0.3\rangle$ & $\langle 0.4,0.2\rangle$ \\
$A_{3}$ & $\langle 0.4,0.3\rangle$ & $\langle 0.6,0.2\rangle$ & $\langle 0.6,0.3\rangle$ \\
$A_{4}$ & $\langle 0.4,0.4\rangle$ & $\langle 0.7,0.2\rangle$ & $\langle 0.6,0.3\rangle$ \\
$A_{5}$ & $\langle 0.6,0.1\rangle$ & $\langle 0.3,0.4\rangle$ & $\langle 0.4,0.3\rangle$ \\
$A_{6}$ & $\langle 0.6,0.3\rangle$ & $\langle 0.3,0.3\rangle$ & $\langle 0.7,0.2\rangle$ \\
\hline
\end{tabular}

TABLE 20: Test decision-making matrix $T_{2}$ in situation $Z_{2}$.

\begin{tabular}{lccc}
\hline & $I_{1}$ & $I_{2}$ & $I_{3}$ \\
\hline$A_{1}$ & $\langle 0.5,0.4\rangle$ & $\langle 0.4,0.3\rangle$ & $\langle 0.4,0.3\rangle$ \\
$A_{2}$ & $\langle 0.6,0.1\rangle$ & $\langle 0.5,0.4\rangle$ & $\langle 0.6,0.3\rangle$ \\
$A_{3}$ & $\langle 0.5,0.3\rangle$ & $\langle 0.4,0.3\rangle$ & $\langle 0.5,0.1\rangle$ \\
$A_{4}$ & $\langle 0.5,0.3\rangle$ & $\langle 0.7,0.2\rangle$ & $\langle 0.6,0.2\rangle$ \\
$A_{5}$ & $\langle 0.7,0.2\rangle$ & $\langle 0.4,0.3\rangle$ & $\langle 0.5,0.3\rangle$ \\
$A_{6}$ & $\langle 0.5,0.3\rangle$ & $\langle 0.6,0.1\rangle$ & $\langle 0.6,0.3\rangle$ \\
\hline
\end{tabular}

$\left(I_{2}\right)$, and rescue cost $\left(I_{3}\right)$. There are two possible situations: (1) secondary disaster will occur $\left(Z_{1}\right)$; (2) secondary disaster will not occur $\left(Z_{2}\right)$. The probabilities for the above two situations are $p\left(Z_{1}\right)=0.3, p\left(Z_{2}\right)=0.7$.

The decision-making process based on the proposed method is as follows.

Step 1. Experts express their IF decision-making matrices $D_{1}$ and $D_{2}$ in two different situations as shown in Tables 17 and 18.

Step 2. According to the past case base, two test decisionmaking matrices $T_{1}$ and $T_{2}$ are provided in different situations $\left(Z_{1}, Z_{2}\right)$, respectively (as shown in Tables 19 and 20).

Then, according to past successful decision-making case, the alternatives are specified into the following 3 categories: $V_{1}=\left\{A_{4}\right\}, V_{2}=\left\{A_{1}, A_{2}, A_{3}, A_{6}\right\}$, and $V_{3}=\left\{A_{5}\right\}$, where $V_{1}, V_{2}$, and $V_{3}$ mean "good," "acceptable," and "poor," respectively.
TABLE 21: Score matrix $S_{1}$.

\begin{tabular}{lccc}
\hline & $I_{1}$ & $I_{2}$ & $I_{3}$ \\
\hline$A_{1}$ & 0.31 & 0.53 & 0.3 \\
$A_{2}$ & -0.21 & -0.32 & 0.19 \\
$A_{3}$ & 0.07 & 0.45 & 0.3 \\
$A_{4}$ & -0.05 & 0.53 & 0.3 \\
$A_{5}$ & 0.67 & -0.22 & 0.04 \\
$A_{6}$ & 0.31 & -0.11 & 0.53 \\
\hline
\end{tabular}

TABle 22: Score matrix $S_{2}$.

\begin{tabular}{lccc}
\hline & $I_{1}$ & $I_{2}$ & $I_{3}$ \\
\hline$A_{1}$ & 0.09 & 0.06 & 0.04 \\
$A_{2}$ & 0.67 & 0.08 & 0.3 \\
$A_{3}$ & 0.2 & 0.06 & 0.57 \\
$A_{4}$ & 0.2 & 0.53 & 0.44 \\
$A_{5}$ & 0.54 & 0.06 & 0.18 \\
$A_{6}$ & 0.2 & 0.66 & 0.3 \\
\hline
\end{tabular}

TABle 23: Prospect value matrix $W$.

\begin{tabular}{lccc}
\hline & $I_{1}$ & $I_{2}$ & $I_{3}$ \\
\hline$A_{1}$ & 0.178 & 0.23 & 0.14 \\
$A_{2}$ & 0.19 & -0.2 & 0.26 \\
$A_{3}$ & 0.16 & 0.2 & 0.44 \\
$A_{4}$ & 0.08 & 0.49 & 0.37 \\
$A_{5}$ & 0.53 & -0.14 & 0.14 \\
$A_{6}$ & 0.24 & 0.27 & 0.37 \\
\hline
\end{tabular}

TABle 24: Expectation matrix $D$ and $E\left(A^{*}\right)$.

\begin{tabular}{lccc}
\hline & $I_{1}$ & $I_{2}$ & $I_{3}$ \\
\hline$X_{1}$ & $\langle 0.53,0.37\rangle$ & $\langle 0.57,0.32\rangle$ & $\langle 0.4,0.3\rangle$ \\
$X_{2}$ & $\langle 0.63,0.16\rangle$ & $\langle 0.5,0.4\rangle$ & $\langle 0.5,0.3\rangle$ \\
$X_{3}$ & $\langle 0.55,0.3\rangle$ & $\langle 0.5,0.27\rangle$ & $\langle 0.6,0.3\rangle$ \\
$X_{4}$ & $\langle 0.47,0.2\rangle$ & $\langle 0.74,0.14\rangle$ & $\langle 0.63,0.23\rangle$ \\
\hline$E\left(A^{*}\right)$ & $\langle 0.47,0.33\rangle$ & $\langle 0.7,0.2\rangle$ & $\langle 0.6,0.23\rangle$ \\
\hline
\end{tabular}

Step 3. The experts find the best alternative $A^{*}=A_{4}$.

Step 4. According to (5), convert the IF decision-making matrices $T_{1}$ and $T_{2}$ into score matrices $S_{1}$ and $S_{2}$, respectively, as shown in Tables 21 and 22.

Step 5. The prospect value matrix $W$ is obtained as shown in Table 23.

Step 6. By using the program (P1), we get the most descriptive weighting vector $w^{*}=(0.48,0.35,0.17)$ and the thresholds $R_{1}=0.84, R_{2}=0.51$.

Step 7. Integrate all the IFN decision-making matrices $D_{1}$ and $D_{2}$ in original decision-making problem and $A^{*}$ into expectation matrix $D$ and $E\left(A^{*}\right)$, respectively, as shown in Table 24 . 
TABLE 25: Real number matrix $D^{\prime}$ and value vector $E\left(A^{*}\right)$.

\begin{tabular}{lccc}
\hline & $I_{1}$ & $I_{2}$ & $I_{3}$ \\
\hline$X_{1}$ & 0.14 & 0.18 & 0.04 \\
$X_{2}$ & 0.54 & 0.02 & 0.18 \\
$X_{3}$ & 0.25 & 0.08 & 0.3 \\
$X_{4}$ & 0.3 & 0.57 & 0.42 \\
\hline$E\left(A^{*}\right)$ & 0.11 & 0.46 & 0.39 \\
\hline
\end{tabular}

Step 8. Transform the IFN matrix $D$ and $A^{*}$ into real number information by the proposed score function, shown in Table 25.

Step 9. Calculate the grey incidence degree between alternatives $X_{i}(i=1,2,3,4)$ and $A^{*}$ with (17).

We obtain $r\left(X_{1}, A^{*}\right)=0.716, r\left(X_{2}, A^{*}\right)=0.412$, $r\left(X_{3}, A^{*}\right)=0.615$, and $r\left(X_{4}, A^{*}\right)=0.721$. Since $R_{1}=0.84$ and $R_{2}=0.51$, we can obtain that $X_{1}, X_{3}$, and $X_{4}$ belong to $V_{2}$ and $X_{2}$ belongs to $V_{3}$. The ranking result is $X_{4}>X_{1}>$ $X_{3}>X_{2}$.

4.3. Advantages of the Proposed Method. We illustrate the advantages by comparing with some traditional MCDM methods in the following:

(1) Monte Carlo simulation method was used in [2] to construct a decision-making model for fuzzy stochastic decision-making problems in groundwater-agricultural systems. In [3], a fuzzy stochastic dynamic fractional programming was proposed to deal with stochastic fuzzy dual uncertainty. In [1], a multiple objective programming was discussed for interactive fuzzy stochastic programming issues, and some interactive algorithms were proposed to seek a satisfying solution of DMs. These methods pay more attention to programming or simulating methods but have not considered that DMs are bounded rational facing stochastic uncertainty. Compared with these methods, our proposed method considers DM's bounded rationality when DM faces stochastic uncertainties. As a result, we use PT to aggregate information and obtain the criteria weights and clustering thresholds, which are applied to classify or rank alternatives.

(2) In [7, 18, 24-26], behavioral theories such as PT and regret theory were considered to analyze the bounded rationality of DMs. But these methods paid close attention to decision-making matrices and ignored the DMs' experiences or past successful cases. The proposed method is based on past successful cases and CBR to classify or rank alternatives, which could help DMs make a quick decision when facing uncertain or difficult decision-making problems. This decision-making pattern is particularly suited to decision-making problems with high risk and uncertainty, such as venture investment and emergency rescue.
In conclusion, our proposed method is aimed at acquiring a satisfactory solution considering both DMs' bounded rationality and experiences or past successful cases. As a result, it would be a sound method to guide people to make decisions.

\section{Conclusions}

In this study, we investigated a novel stochastic intuitionistic fuzzy decision-making method based on PT and CBR methods. We first introduced a new score function for IFN. Then, based on the test matrices, the PT and grey incidence analysis (GIA), we constructed a mathematical programming model to calculate the weights of criteria according to the idea of CBR. Moreover, on the basis of the weights of criteria and threshold values obtained by CBR, we introduced a method to classify or rank the alternatives. Two examples have been given to show the advantages of the proposed method.

Our proposed method is to seek satisfactory solutions considering both DMs' bounded rationality and the past successful cases or experiences. In fact, when people are making decisions with high risk or stochastic uncertainties, such as finance investment or emergency rescue, it is very difficult or even impossible to make an optimal decision owing to the time pressure and uncertain information. In this case, DMs hope to acquire a compromise satisfactory decision through past successful cases. Therefore, our proposed method has practical implications and can be applied broadly in many fields.

\section{Conflicts of Interest}

The authors declare that there are no conflicts of interest regarding the publication of this paper.

\section{Acknowledgments}

This work was supported by the National Natural Science Foundation of China (Project nos. 71401064 and 71371107) and the Leverhulme Trust International Network on Grey Systems and Applications (IN-2014-020).

\section{References}

[1] M. Inuiguchi, K. Kato, and H. Katagiri, "Fuzzy multi-criteria optimization: possibilistic and fuzzy/stochastic approaches," in Multiple Criteria Decision Analysis, pp. 851-902, Springer, New York, NY, USA, 2016.

[2] Y. H. Subagadis, N. Schütze, and J. Grundmann, "A fuzzystochastic modeling approach for multiple criteria decision analysis of coupled groundwater-agricultural systems," Water Resources Management, vol. 30, no. 6, pp. 2075-2095, 2016.

[3] X. Zhang, G. Huang, H. Zhu, and Y. Li, "A fuzzy-stochastic power system planning model: reflection of dual objectives and dual uncertainties," Energy, vol. 123, pp. 664-676, 2017.

[4] V. Mohagheghi, S. M. Mousavi, and B. Vahdani, "A new multiobjective optimization approach for sustainable project portfolio selection: a real-world application under interval-valued fuzzy environment," Iranian Journal of Fuzzy Systems, vol. 13, no. 6, pp. 41-68, 2016. 
[5] P. Soleymani, S. M. Mousavi, B. Vahdani, and A. Aboueimehrizi, "A new fuzzy multi-objective optimisation method with desirability function under uncertainty," International Journal of Applied Decision Sciences, vol. 9, no. 1, pp. 100-120, 2016.

[6] S.-M. Yu, J. Wang, and J.-Q. Wang, "An interval type-2 fuzzy likelihood-based MABAC approach and its application in selecting hotels on a tourism website," International Journal of Fuzzy Systems, vol. 19, no. 1, pp. 47-61, 2017.

[7] J.-Q. Wang, J.-J. Kuang, J. Wang, and H.-Y. Zhang, "An extended outranking approach to rough stochastic multi-criteria decision-making problems," Cognitive Computation, vol. 8, no. 6, pp. 1144-1160, 2016.

[8] K. T. Atanassov, "Intuitionistic fuzzy sets," Fuzzy Sets and Systems, vol. 20, no. 1, pp. 87-96, 1986.

[9] B. Vahdani, S. M. Mousavi, R. Tavakkoli-Moghaddam, and H. Hashemi, "A new design of the elimination and choice translating reality method for multi-criteria group decision-making in an intuitionistic fuzzy environment," Applied Mathematical Modelling. Simulation and Computation for Engineering and Environmental Systems, vol. 37, no. 4, pp. 1781-1799, 2013.

[10] H. Hashemi, J. Bazargan, and S. M. Mousavi, "A compromise ratio method with an application to water resources management: an intuitionistic fuzzy set," Water Resources Management, vol. 27, no. 7, pp. 2029-2051, 2013.

[11] S. M. Mousavi, B. Vahdani, and S. Sadigh Behzadi, "Designing a model of intuitionistic fuzzy VIKOR in multi-attribute group decision-making problems," Iranian Journal of Fuzzy Systems, vol. 13, no. 1, pp. 45-65, 2016.

[12] S. M. Mousavi, S. Mirdamadi, A. Siadat, J. Dantan, and R. Tavakkoli-Moghaddam, "An intuitionistic fuzzy grey model for selection problems with an application to the inspection planning in manufacturing firms," Engineering Applications of Artificial Intelligence, vol. 39, pp. 157-167, 2015.

[13] S.-M. Chen and C.-H. Chang, "A novel similarity measure between Atanassov's intuitionistic fuzzy sets based on transformation techniques with applications to pattern recognition," Information Sciences, vol. 291, pp. 96-114, 2015.

[14] Y. Song, X. Wang, and H. Zhang, "A distance measure between intuitionistic fuzzy belief functions," Knowledge-Based Systems, vol. 86, pp. 288-298, 2015.

[15] Z. Xu and H. Liao, "A survey of approaches to decision making with intuitionistic fuzzy preference relations," Knowledge-Based Systems, vol. 80, pp. 131-142, 2015.

[16] H. Hashemi, J. Bazargan, S. M. Mousavi, and B. Vahdani, "An extended compromise ratio model with an application to reservoir flood control operation under an interval-valued intuitionistic fuzzy environment," Applied Mathematical Modelling. Simulation and Computation for Engineering and Environmental Systems, vol. 38, no. 14, pp. 3495-3511, 2014.

[17] J.-Q. Wang, K.-J. Li, and H.-Y. Zhang, "Interval-valued intuitionistic fuzzy multi-criteria decision-making approach based on prospect score function," Knowledge-Based Systems, vol. 27, pp. 119-125, 2012.

[18] Y. Cao, H. Zhou, and J. Wang, "An approach to interval-valued intuitionistic stochastic multi-criteria decision-making using set pair analysis," International Journal of Machine Learning and Cybernetics, pp. 1-12, 2016.

[19] P. Wang, X. Xu, J. Wang, and C. Cai, "Some new operation rules and a new ranking method for interval-valued intuitionistic linguistic numbers," Journal of Intelligent \& Fuzzy Systems, vol. 32, no. 1, pp. 1069-1078, 2017.
[20] S. Yu, J. Wang, and J. Wang, "An extended TODIM approach with intuitionistic linguistic numbers," International Transactions in Operational Research, 2016.

[21] S.-P. Wan and D.-F. Li, "Fuzzy mathematical programming approach to heterogeneous multiattribute decision-making with interval-valued intuitionistic fuzzy truth degrees," Information Sciences, vol. 325, pp. 484-503, 2015.

[22] J. Q. Wang and J. J. Li, "Intuitionistic random multi-criteria decision-making approach based on score functions," Control and Decision, vol. 25, no. 9, pp. 1297-1306, 2010.

[23] P. Li, S. F. Liu, and J. J. Zhu, "Intuitionistic fuzzy stochastic multicriteria decision-making methods based on prospect theory," Control and Decision, vol. 27, no. 11, pp. 1601-1606, 2012.

[24] H. Zhou, J. Wang, and H. Zhang, "Stochastic multicriteria decision-making approach based on SMAA-ELECTRE with extended gray numbers," International Transactions in Operational Research, 2017.

[25] H. Zhou, J. Wang, and H. Zhang, "Grey stochastic multicriteria decision-making based on regret theory and TOPSIS," International Journal of Machine Learning and Cybernetics, vol. 8, no. 2, pp. 651-664, 2017.

[26] H. Zhou, J. Q. Wang, and H. Y. Zhang, "Grey stochastic multicriteria decision-making approach based on prospect theory and distance measures," The Journal of Grey System, vol. 29, pp. 15-33, 2017.

[27] Y. Chen, D. M. Kilgour, and K. W. Hipel, "Screening in multiple criteria decision analysis," Decision Support Systems, vol. 45, no. 2, pp. 278-290, 2008.

[28] Y.-T. Chen and M.-C. Chiu, "A case-based method for serviceoriented value chain and sustainable network design," Advanced Engineering Informatics, vol. 29, no. 3, pp. 269-294, 2015.

[29] C. Koo and T. Hong, "A dynamic energy performance curve for evaluating the historical trends in the energy performance of existing buildings using a simplified case-based reasoning approach," Energy and Buildings, vol. 92, pp. 338-350, 2015.

[30] A. Yan, H. Shao, and P. Wang, "A soft-sensing method of dissolved oxygen concentration by group genetic case-based reasoning with integrating group decision making," Neurocomputing, vol. 169, pp. 422-429, 2015.

[31] Z.-P. Fan, Y.-H. Li, and Y. Zhang, "Generating project risk response strategies based on CBR: a case study," Expert Systems with Applications, vol. 42, no. 6, pp. 2870-2883, 2015.

[32] C. Evans, "Re-thinking case-based assessments in business management education," International Journal of Management Education, vol. 14, no. 2, pp. 161-166, 2016.

[33] Z. Xu, "Intuitionistic fuzzy aggregation operators," IEEE Transactions on Fuzzy Systems, vol. 15, no. 6, pp. 1179-1187, 2007.

[34] S. M. Chen and J. M. Tan, "Handling multicriteria fuzzy decision-making problems based on vague set theory," Fuzzy Sets and Systems, vol. 67, no. 2, pp. 163-172, 1994.

[35] J. Ye, "Improved method of multicriteria fuzzy decision-making based on vague sets," Computer Aided Design, vol. 39, no. 2, pp. 164-169, 2007.

[36] P. D. Liu, F. Jin, X. Zhang, Y. Su, and M. Wang, "Research on the multi-attribute decision-making under risk with interval probability based on prospect theory and the uncertain linguistic variables," Knowledge-Based Systems, vol. 24, no. 4, pp. 554-561, 2011.

[37] L. Sun and M. Widdicks, "Why do employees like to be paid with Options?: A multi-period prospect theory approach," Journal of Corporate Finance, vol. 38, pp. 106-125, 2016. 
[38] J. Yang and G. Jiang, "Development of an enhanced route choice model based on cumulative prospect theory," Transportation Research Part C: Emerging Technologies, vol. 47, no. 2, pp. 168178, 2014.

[39] Y. Liu, Z.-P. Fan, and Y. Zhang, "Risk decision analysis in emergency response: a method based on cumulative prospect theory," Computers and Operations Research, vol. 42, pp. 75-82, 2014.

[40] L. Wang, Z.-X. Zhang, and Y.-M. Wang, "A prospect theorybased interval dynamic reference point method for emergency decision making," Expert Systems with Applications, vol. 42, no. 23, pp. 9379-9388, 2015.

[41] S. F. Liu and Y. Lin, Grey Information: Theory and Practical Applications, Springer, London, UK, 2006.

[42] X.-H. Xu, Z.-J. Du, and X.-H. Chen, "Consensus model for multi-criteria large-group emergency decision making considering non-cooperative behaviors and minority opinions," Decision Support Systems, vol. 79, pp. 150-160, 2015. 


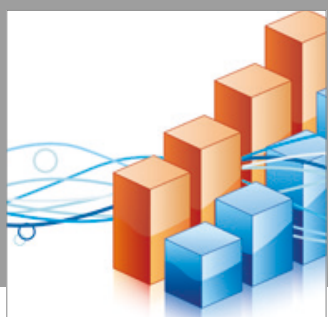

Advances in

Operations Research

vatersals

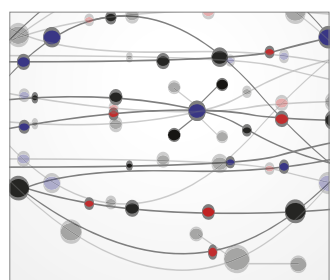

\section{The Scientific} World Journal
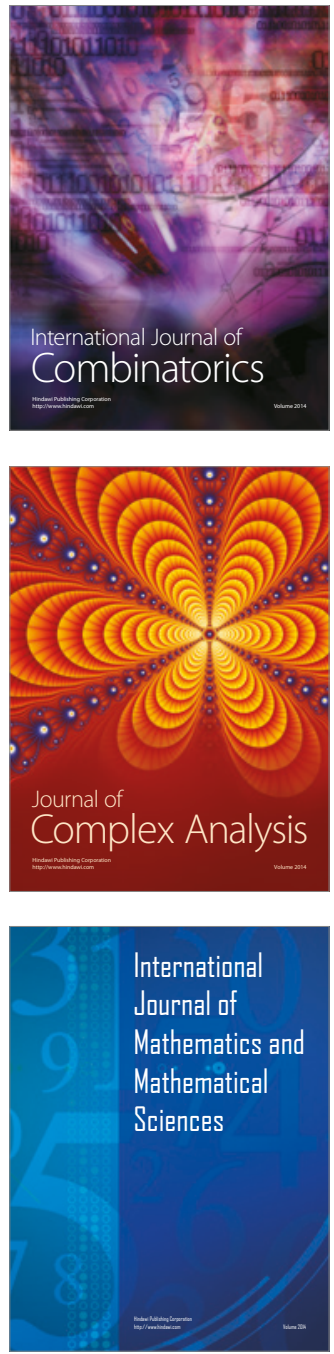
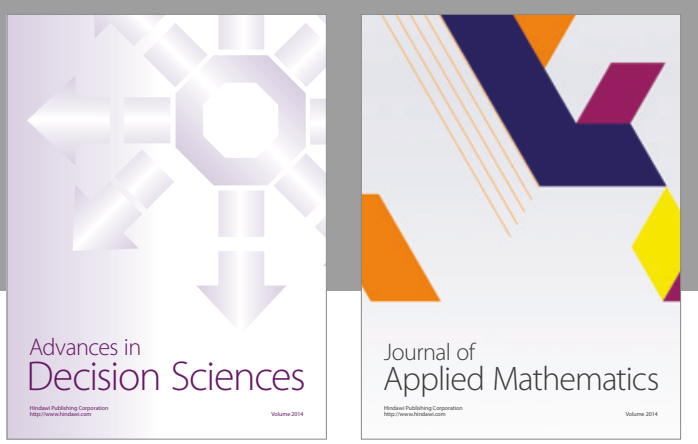

Algebra

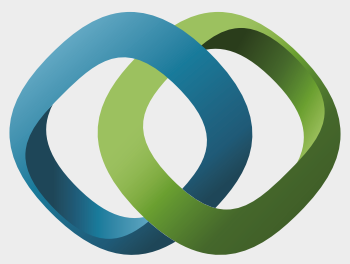

\section{Hindawi}

Submit your manuscripts at

https://www.hindawi.com
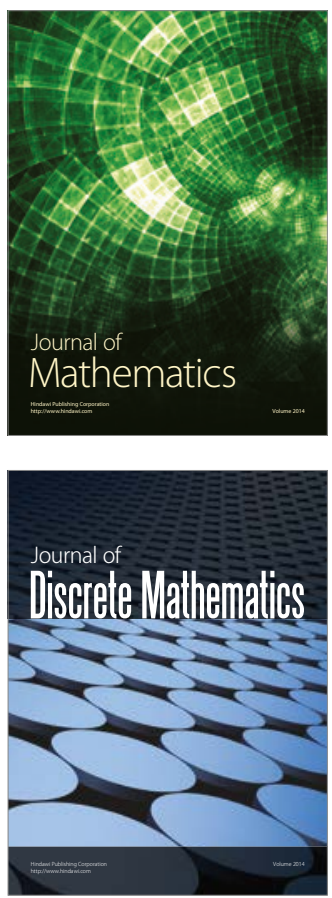

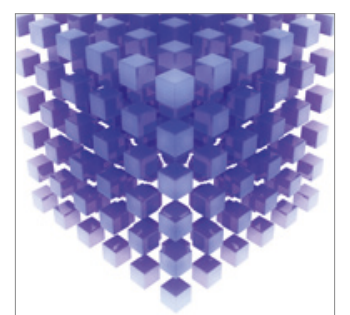

Mathematical Problems in Engineering
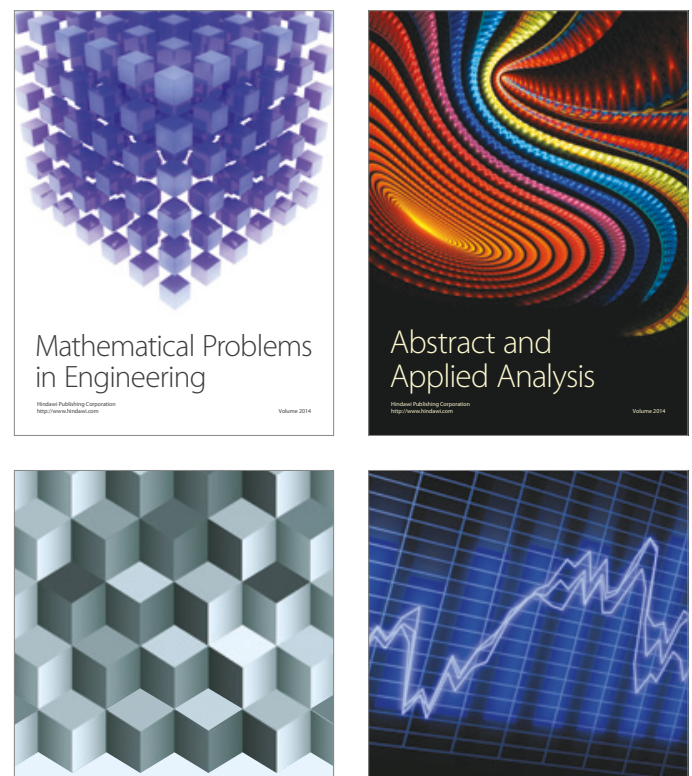

Journal of

Function Spaces

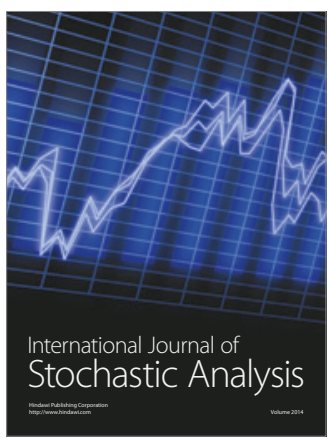

Probability and Statistics
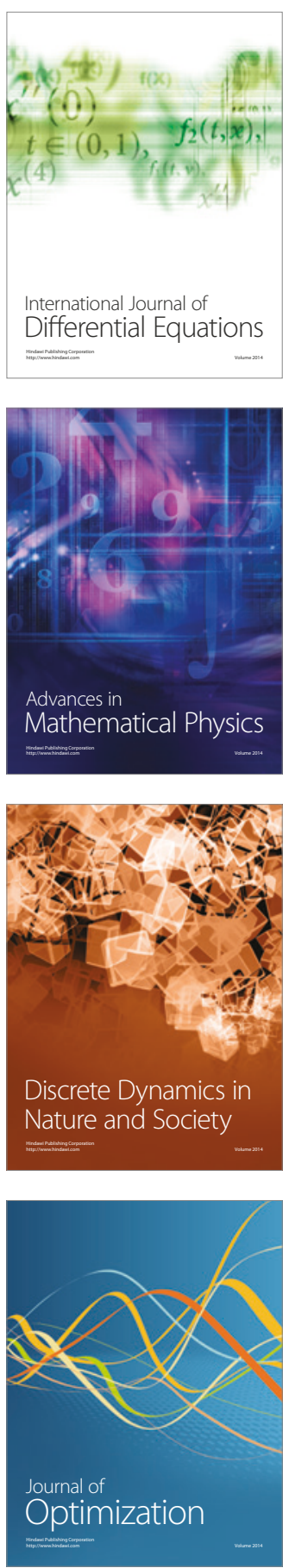